\title{
Evaluation of water loss and solute uptake during osmotic treatment of white radishes (Raphanus sativus L.) in salt-
} sucrose solution

\author{
Nguyen Minh Thuy ${ }^{1 *}$, Nguyen Thi Ngoc Tham ${ }^{1}$, Vo Quang Minh ${ }^{2}$, Pham Thanh Vu ${ }^{2}$ \& Ngo Van Tai ${ }^{1}$ \\ ${ }^{1}$ Department of Food Technology, College of Agriculture, Can Tho University, Can Tho city, 900000, Vietnam \\ ${ }^{2}$ Department of Land Resources, College of Environment and Natural Resources, Can Tho University, Can Tho city, 900000, Vietnam \\ ^Email: nmthuy@ctu.edu.vn
}

OPEN ACCESS

\section{ARTICLE HISTORY}

Received: 01 August 2021

Accepted: 30 October 2021

Available online

Version 1.0 (Early Access): 25 December 2021 Version 2.0:01 January 2022

\section{Check for updates}

\section{Additional information}

Peer review: Publisher thanks Sectional Editor and the other anonymous reviewers for their contribution to the peer review of this work.

Reprints \& permissions information is available at https://horizonepublishing.com/ journals/index.php/PST/open_access_policy

Publisher's Note: Horizon e-Publishing Group remains neutral with regard to jurisdictional claims in published maps and institutional affiliations.

Indexing: Plant Science Today, published by Horizon e-Publishing Group, is covered by Scopus, Web of Science, BIOSIS Previews, Clarivate Analytics, etc. See https:// horizonepublishing.com/journals/index.php/ PST/indexing_abstracting

Copyright: () The Author(s). This is an openaccess article distributed under the terms of the Creative Commons Attribution License, which permits unrestricted use, distribution and reproduction in any medium, provided the original author and source are credited (https://creativecommons.org/licenses/ by/4.0/)

\section{CITE THIS ARTICLE}

Thuy N M, Tham N T N, Minh V O, Vu P T, Tai N $\checkmark$. Evaluation of water loss and solute uptake during osmotic treatment of white radishes (Raphanus sativus L.) in salt-sucrose solution. Plant Science Today. 2022;9(1):191-197. https://doi.org/10.14719/pst.1422

\begin{abstract}
White radish, scientifically known as Raphanus sativus L., is a yearly vegetable. Currently, it was being grown and widely used in the world, including Vietnam. These plants have been used as food or food processing. The osmotic treatment of vegetables involves the removal of water from plants in which the solids from the osmotic solution are transported to the plant material by osmosis. By this procedure, sucrose and saline solution are usually performed. White radishes were dehydrated in different hypertonic solutions by combined sucrose and $\mathrm{NaCl}$ at three different concentrations, including 9 runs. Mass transfer behaviour was applied according to three common models such as Fick's second law, Weibull and Peleg's equations based on the change of moisture and solid content of white radish during osmotic dehydration. The obtained results showed that the mass transfer was fast at initial stage and became slowly at the later stage. The effective moisture $\left(D_{m}\right)$ and solid diffusivities $\left(D_{s}\right)$ were ranged from 1.0186 to $1.2826 \times 10^{-8}$ and from 1.0692 to $2.3322 \times 10^{-8}\left(\mathrm{~m}^{2} / \mathrm{s}\right)$ respectively. The Peleg's equation was found to be the best fitting for water loss and solid uptake thanks to the high determination coefficient $(>97.64 \%$ ) and the low average relative error $(<3.174 \%)$. Raised up solution concentration resulted in higher water loss and mass gain.
\end{abstract}

\section{Keywords}

White radish, osmotic treatment, salt-sucrose solution, water loss, solid gain

\section{Introduction}

White radishes are popular and widely cultivated root vegetables in the world, which occupy an important place in human nutrition. The consumption of white radishes has attracted research interest because they are rich in valuable nutritional components as carbohydrate, vitamin and minerals which promote human health (1). The vitamin $C$ in white radish is high which has a positive effect as strengthen and resistance con the body $(2,3)$. White radish is also known as "white ginseng", because of its many good uses for human health and they also have a positive influence on preventing diseases (2-4). It contains glucosinolates and phenolic compounds which were function as anticancer, antibacterial, antioxidant (5), liver detoxification (6). In recent years, intermediate moisture foods have been developed for human use, which draws attention from many researchers. The foodstuffs are considered as an intermediate product, which was produced by osmotic dehydration. These products have several advantages such as a higher nutritional content than any other treatment method because os- 
motic dehydration has little effect on the various internal components of food (7). In addition, it could use immediately or for further processing. Therefore, applying osmotic dehydration is the right choice for white radish so that they can keep their good properties but also can produce products with high nutritional and sensory value.

Osmotic treatment or dehydration is an important and efficient process in food processing to save energy and money (7). During this process, the product is immersed in the hypertonic solution which enables the partial removal of water (8). Due to the difference of osmotic pressure between products and solutions that made to occurs the simultaneous counter-current mass transfer includes water loss and solid uptake $(9,10)$. The choice of an osmotic agent should consider because it affects not only the kinetics of mass transfer properties but can also be important for the sensory and nutritional value of the product. Characteristics commonly found in osmotic agents are low molecular weight, acceptable taste, smell and stability to other food ingredients. Moreover, the available and the price of used materials also need to consider, therefore using sugar and salt or combined two of them is a good choice for the dehydration process. As far as the hypertonic solution is concerned, the most important factors are the chemical composition and the concentration of the solution (11).

Various models have been developed by researchers to predict the mass transfer behaviour during the osmotic process. To describe the mass transport phenomena, Fick's second law has been developed as a mathematical model by various researchers (12). It has been developed two-parameter absorption equation based on Fick's law of diffusion (13). However, some models are simple and validate the experimental data, but their use is limited to certain cases and they do not take into account the mechanism in which the results depend, the Weibull equation also developed. Some other models with very complex mechanisms find it difficult to represent the experimental validation owing to the number of parameters involved in the models. The work aimed to investigate a predictive model of the water loss and solute uptake during the osmotic dehydration of white radishes and examine the predictive capacity of Fick, Weibull and Peleg's equation to the experimental data.

\section{Materials and Methods}

\section{Sample preparation}

The white radishes (Raphanus sativus L.) were bought at local market in Can Tho city, Vietnam. After collection, these were washed, peeled and cut into shape (length $x$ diameter $=12 \times 4 \mathrm{~cm}$ ) as a constant parameter during osmotic treatment.

The hypertonic solutions were prepared by randomized combining three levels of sugar $(10 ; 12.5 ; 15 \% \mathrm{w} / \mathrm{v})$ and salt $(2 ; 3 ; 4 \% \mathrm{w} / \mathrm{v})$.

The prepared white radishes were immersed in treatment solution at ambient temperature with a ratio of sample: solution was 1:20 (w/v) in order to avoid the influence of the changes in the concentration of solution at osmotic period. The duration of treatment was $7 \mathrm{hrs}$; the sample was randomly taken out after hourly interval. The moisture content and the solid content measurement of treated sample was measured after washing the osmotic agents and removing the surface water by absorbent paper to give the exactly results.

\section{Mass transfer kinetics}

The calculation of the water loss (WL) and solid gain (SG) were followed by Equations 1 and 2 based on the moisture and the solid content of sample respectively (14).

$$
\begin{gathered}
W L=\frac{M_{D} X_{D}-M_{L} X_{L}}{M_{D}} \times 100 \% \\
S G=\frac{M_{L} S_{L}-M_{D} S_{D D}}{M_{D}} \times 100 \%
\end{gathered}
$$

where $M_{0}$ and $M_{t}$ are the initial weight $(g)$ and the weight at time $(\mathrm{t})$ of the treated white radishes respectively $(\mathrm{g}) ; \mathrm{X}_{0}$ and $X_{t}$ are the initial moisture content (\%) and at time (t) of the treated white radish respectively; $S_{0}$ and $S_{t}$ are the initial and time $(\mathrm{t})$ solid content of the treated white radish respectively (\%).

The moisture and solid ratio (MR and SR, respectively) were calculated as described by Doymaz and İsmail (14) (Equation 3 and 4).

$$
\begin{aligned}
& M R=\frac{W L-W L_{E}}{W L_{E}} \\
& S R=\frac{\$ R-\$ R_{m}}{S R_{E}}
\end{aligned}
$$

where WL and SG are the water loss and solid gain when the osmotic dehydration processes are in equilibrium. Equation 5 and 6 for calculation of $W L_{e}$ and $S G_{e}$ respectively (15).

$\frac{1}{W L}=\frac{1}{S_{1} t W L_{E}}+\frac{1}{W L_{a}}$

$\frac{1}{S G}=\frac{1}{S_{2}+S G_{\mathbb{E}}}+\frac{1}{S G_{1 E}}$

where $S_{1}$ and $S_{2}$ are rate constants and $t$ is the time of each measurement.

\section{Fick's second law of diffusion}

Fick's second law of diffusion was used to describe the mass transfer kinetics characteristics during the osmotic dehydration; however, for long osmotic periods in this study, the models could be simplified into Equation 7 (16).

$M R=\frac{8}{\pi^{2}} \exp \left(-\frac{\pi^{2} D_{x} t}{4 L^{2}}\right)$

where $D_{m}$ and $D_{s}$ are the effective moisture and solid diffusivity $\left(\mathrm{m}^{2} \mathrm{~s}^{-1}\right)$ respectively, $t$ is the osmotic dehydration time $(\mathrm{s})$ and $\mathrm{L}$ is the half-thickness of the samples $(\mathrm{m})$.

\section{Weibull model}

Weibull mathematical model was selected to fit the experiment data from osmotic dehydration process based on previous researches $(17,18)$ (Equation 8$)$. 


$$
M R=\exp \left(-\left(\frac{\mathrm{t}}{\beta}\right)^{\mathrm{u}}\right)
$$

where $\alpha$ and $\beta$ are the shape and scale parameters of the Weibull model respectively.

\section{Peleg's equation}

The Peleg's equation was applied to describe the water loss/solid uptake curves that asymptotic equilibrium (13), which proposes a two parameter non-exponential model as described by the Equation $9(19,20)$.

$M_{\mathrm{t}}=M_{0}-\frac{\mathrm{t}}{\mathrm{k}_{1}+\mathrm{k}_{2} \mathrm{t}}$

where $M_{t}$ is the amount of water or solids at time $t, g ; M_{0}$ is the initial amount of water or solids, $g$; $t$ is the time, $h ; k_{1}$ and $k_{2}$ are Peleg's constants.

The Statgraphics centurions XV.I software was used for a non-linear regression analysis. The coefficient of determination $\left(R^{2}\right)$ was used to evaluate the goodness of fit and was calculated in this study by using the Equation 10.

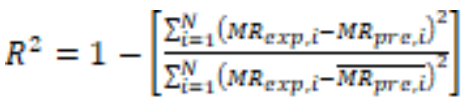

The average relative error was used as a criterion to evaluate the best fitting (Equation 11) (21).

$P(\%)=\frac{100}{n} \sum_{i=1}^{n} \frac{\left\|V_{R}-v_{c}\right\|}{v_{c}}$

where $P$ is the average relative error, dimensionless; $n$ is the number of experimental data; $V_{e}$ is the experimental value (water loss or salt gain); $V_{c}$ is the calculated value (water loss or salt gain).

\section{Results and Discussion}

The two main processes during osmotic dehydration are water loss and solid gain, the calculation of these processes is based on the change of moisture and solid content of white radishes. It could see clearly that the high rate of water removal and solid uptake was observed at the initial stage, the slower process was followed in the later stage (Fig. 1). It also found that moisture loss, solid gain rise as the immersion time proceeds and reaches equilibrium condition after a particular period. Comparatively the solid gain was lower than moisture loss in all cases. The signifi- cant difference between the pressure of hypertonic solution and the food's cell membrane drives the movement of water and solid. The rapid loss at the beginning of the process is apparently due to the large pressure gradient between the dilute sap of the fresh fruit and the surrounding hypertonic medium $(22,23)$. The concentration of the solution is difference that resulted in the different in osmotic pressure gradients and hence, the higher concentration used made the higher water loss (or mass uptake) during the treatment period. The results also showed that by choosing the appropriate medium with a higher concentration, it is possible to promote the dehydration process. However, the content of solids uptake was also considered. For the mixed permeation medium, the simultaneous effect of salt and sugar on white radish mass transfer was also observed (21).

The use of sodium chloride promotes the dehydration process due to its ability to reduce water activity combined with its low molecular weight allowing higher penetration into food structures. However, the use of salt is also limited because salt gives the product a salty taste, resulting in a decrease in sensory value after the process ends. In addition, using sugar in the solution not only reduces the saltiness but also sucrose allows the formation of a sugar surface layer, which becomes a barrier to water removal and solute absorption $(21,24)$. Selected experimental and predicted curve for both mass transfer processes as water loss and solid uptake data based on three common equations including Peleg, Fick and Weibull equations.

The mass transfer behaviour followed Fick's equation and the equation parameters were calculated and shown in Table 1 and 2 . It can be seen that the rate constants and equilibrium water loss values of white radish during osmotic treatment under different concentrations of agents used varied from 0.4859-0.8105 and 19.4668$26.6833 \%$ respectively, whereas the obtained results of the solid gain process were $0.7453-2.1429$ and $7.6247-8.7310 \%$ corresponding to the rate of constant and equilibrium solid gain. A comparison of these data indicates that the value of solid gain is lower than those of water loss, it was in agreement with the earlier results (24). Diffusion is improved by higher solute concentration in osmotic solution. The effective moisture $\left(D_{m}\right)$ as well as solid diffusivities $\left(D_{s}\right)$ were ranged from 1.0186 to $1.2826 \times 10^{-8}$ and from 1.0692 to $2.3322 \times 10^{-8}\left(\mathrm{~m}^{2} / \mathrm{s}\right)$ respectively. This variability in diffusion

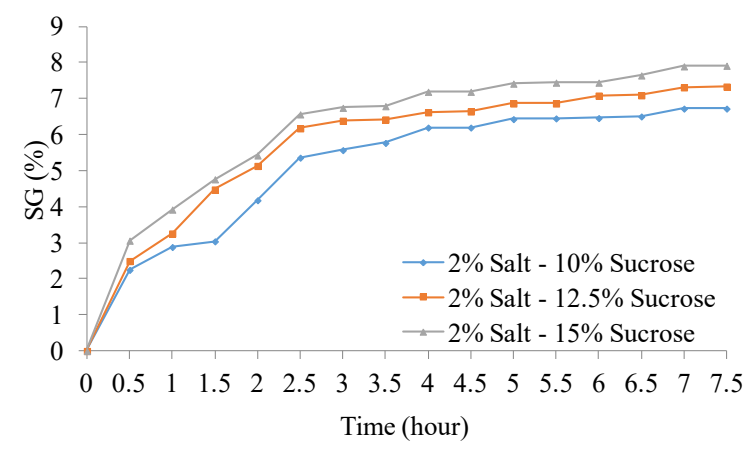



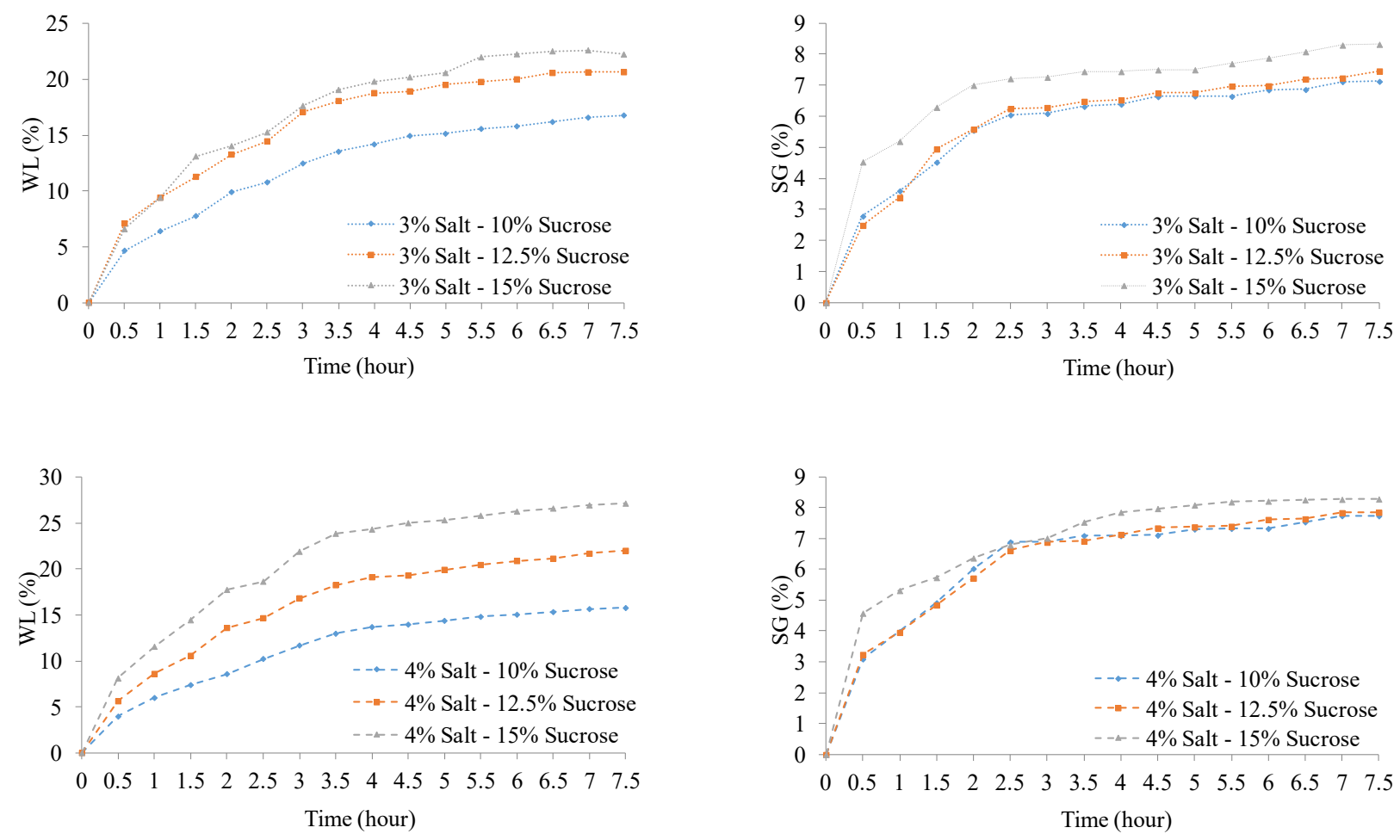

Fig. 1. Water loss (WL, \%) and solid gain (SG, \%) of white radishes during osmotic treatment.

Table 1. Water loss behaviour of white radishes during osmotic treatment by Fick's equation

\begin{tabular}{|c|c|c|c|c|c|c|}
\hline Salt (\%) & Sucrose (\%) & $\mathbf{S}_{1}$ & WL-e & $D_{m} \times 10^{-8}\left(\mathrm{~m}^{2} / \mathrm{s}\right)$ & $\mathbf{R}^{2}(\%)$ & P (\%) \\
\hline & 10 & 0.6666 & 19.5724 & 1.2111 & 97.19 & 5.014 \\
\hline \multirow[t]{3}{*}{2} & 12.5 & 0.6875 & 21.4306 & 1.2826 & 97.28 & 5.323 \\
\hline & 15 & 0.6264 & 26.6833 & 1.1565 & 96.60 & 4.173 \\
\hline & 10 & 0.5858 & 19.3713 & 1.2406 & 96.49 & 6.122 \\
\hline \multirow[t]{2}{*}{3} & 12.5 & 0.8105 & 23.2262 & 1.4481 & 96.13 & 5.788 \\
\hline & 10 & 0.4859 & 19.4668 & 1.0806 & 98.32 & 5.115 \\
\hline \multirow[t]{2}{*}{4} & 12.5 & 0.4996 & 27.3550 & 1.0186 & 98.99 & 3.175 \\
\hline & 15 & 0.6330 & 32.4554 & 1.1756 & 98.27 & 3.993 \\
\hline
\end{tabular}

Note: $W L_{e}$ is the water loss in equilibrium; $S_{1}$ is rate constants; $D_{m}$ is the effective moisture diffusivity

Table 2. Solid gain behaviour of white radishes during osmotic treatment by Fick's equation

\begin{tabular}{|c|c|c|c|c|c|c|}
\hline Salt (\%) & Sucrose (\%) & $\mathbf{S}_{2}$ & $\mathbf{S G}_{\mathrm{e}}$ & $D_{s} \times 10^{-8}\left(m^{2} / s\right)$ & $\mathbf{R}^{2}(\%)$ & $\mathbf{P}(\%)$ \\
\hline & 10 & 0.7453 & 7.6247 & 1.3824 & 90.5730 & 7.618 \\
\hline \multirow[t]{3}{*}{2} & 12.5 & 0.7733 & 8.5889 & 1.1483 & 97.1347 & 3.094 \\
\hline & 15 & 1.0129 & 8.6652 & 1.3854 & 96.4776 & 3.887 \\
\hline & 10 & 1.0210 & 7.9465 & 1.2752 & 97.4329 & 2.753 \\
\hline \multirow[t]{2}{*}{3} & 12.5 & 0.7758 & 8.7310 & 1.0692 & 97.8380 & 3.232 \\
\hline & 10 & 1.0470 & 8.6889 & 1.2500 & 96.8199 & 3.309 \\
\hline \multirow[t]{2}{*}{4} & 12.5 & 1.1095 & 8.5753 & 1.4478 & 95.2097 & 3.869 \\
\hline & 15 & 2.0461 & 8.5141 & 2.3322 & 90.8908 & 4.886 \\
\hline
\end{tabular}

Note: $\mathrm{SG}_{\mathrm{e}}$ is the solid gain in equilibrium; $\mathrm{S}_{2}$ is rate constants; $\mathrm{D}_{\mathrm{a}}$ is the solid diffusivity

coefficient depends on the experimental conditions and cult in comparison of diffusivities reported in previous reprocedures used for the determination of the moisture search because of the different methods of estimation but diffusivity, as well as on the data treatment methods, the also the models conducted with the varieties of the food product's properties, composition, physiological state, and matrix, physical structure and food composition.

heterogeneity of its structure. These values are within the Weibull model based on the change of moisture and range of diffusion value (from $10^{-12}$ to $10^{-8} \mathrm{~m}^{2} / \mathrm{s}$ ) normally solid content of white radish during the osmotic period, the expected for dehydrated foods $(21,25)$. However, it is diffi- 
value of scale $\left(\alpha_{w} \& \alpha_{s}\right)$ and shape $\left(\beta_{w} \& \beta_{s}\right)$ parameters of $10 \%$ sugar. The parameter $1 / k_{1}$ describes the initial mass moisture content and solid content are shown in Table 3. exchange rate, the lower $\mathrm{k}_{1}$ indicates the higher mass trans-

Table 3. Mass transfer characteristics of white radishes during osmotic dehydration by Weibull's equation

\begin{tabular}{|c|c|c|c|c|c|c|c|c|c|}
\hline \multirow{2}{*}{ Salt (\%) } & \multirow{2}{*}{ Sucrose (\%) } & \multicolumn{4}{|c|}{ Water loss } & \multicolumn{4}{|c|}{ Solid gain } \\
\hline & & $\alpha_{w}$ & $\beta_{w}$ & $\mathbf{R}^{2}$ & $\mathbf{P}(\%)$ & $\alpha_{s}$ & $\beta_{s}$ & $\mathbf{R}^{2}$ & $\mathbf{P}(\%)$ \\
\hline & 10 & 0.7163 & 2.6857 & 98.12 & 2.889 & 0.7849 & 2.4189 & 97.79 & 3.169 \\
\hline \multirow[t]{3}{*}{2} & 12.5 & 0.7485 & 2.6400 & 99.11 & 2.117 & 0.6498 & 2.3457 & 98.29 & 2.474 \\
\hline & 15 & 0.7089 & 2.8390 & 98.54 & 2.486 & 0.6709 & 1.8750 & 99.15 & 1.831 \\
\hline & 10 & 0.8054 & 2.9993 & 99.56 & 1.360 & 0.6245 & 1.8155 & 98.84 & 2.149 \\
\hline \multirow{2}{*}{3} & 15 & 0.7423 & 2.7557 & 99.46 & 1.551 & 0.5419 & 0.8636 & 99.07 & 2.003 \\
\hline & 10 & 0.7863 & 3.5184 & 99.34 & 1.661 & 0.6155 & 1.7541 & 98.04 & 2.901 \\
\hline \multirow[t]{2}{*}{4} & 12.5 & 0.7323 & 3.4969 & 99.36 & 1.611 & 0.6611 & 1.7213 & 99.10 & 1.901 \\
\hline & 15 & 0.7214 & 2.8359 & 99.17 & 1.901 & 0.6070 & 1.0022 & 98.88 & 2.264 \\
\hline
\end{tabular}

Note: $\alpha$ and $B$ are the shape and scale parameters of the Weibull model

The value of $\alpha_{w}$ and $a_{s}$ ranged from 0.7089 to 0.8054 and fer. The higher osmotic agents' concentration in solution from 0.5419 to 0.7849 hrs respectively. It was also observed promoted the higher initial mass transfer. This behaviour that the range of $\beta_{w}$ and $\beta_{s}$ corresponded to 2.3000-3.5184 could be due to a cellular response to the osmotic pressure and 0.8636-2.4189as was found in some osmotic research in increment in the osmotic process of apple in salt-sucrose apple (26) and mushrooms (27). The Weibull distribution is solutions (33). Similar findings have been observed in earlireduced thus leading to a shape parameter $(\alpha)$ value lower er studies (34).

than 1. Variation of parameters was analysed for variance between the effects of sugar and salt concentrations used. In these cases, the results showed that both the shape and scale parameters were affected by the salt and sugar concentrations in the osmotic solution. In general, the measure of change in moisture and dry matter content varies inversely with the concentration of salt and sugar in the solution. The variation of parameter a could be compared with the effective diffusion coefficient of the Fick diffusion model since those two parameters are kinetic constants for each model (27). The shape parameter is related to the velocity of the mass transfer at the beginning, the lower is the $\beta$ value, the faster the water loss rate at the beginning. High salt concentration reduces their water holding capacity during salting of milkfish (28), cod and salmon (29).

Like previous studies, the change of moisture reduction and solid uptake curve is typically found $(30,31,32)$. The non-linear regression analysis was applied for calculation of the Peleg's parameters, which are shown in Table 4. It was observed that an inverse relationship between $k_{1}$ and solution concentration can be observed in most of the actual data, except for solutions is combined with $2 \%$ salt and

The osmotic process is simultaneous processes as water reduction and mass uptake. Regarding solid gain by using the solutions evaluated, the results showed that there is a direct relationship between solution concentration and the ability to boost solid gain during an osmotic process. The equilibrium points of osmosis are reaching when the gradient pressure of product and solution become equal. The $k_{2}$ parameter did not describe a trend with the raise of concentration for water loss, it was described as the equilibrium mass transfer point. Adding sucrose to the solution resulted in the increase of the parameter for water loss, while salt gain showed the inverse behaviour. However, higher concentrations gave declined $k_{2}$ for solid gain. The above is consistent with that, the difference in osmotic potential between the solution and the sample will result in a higher rate of solute and water diffusion $(21,35)$.

Experimental data within the dynamic segments of SG and WL and away from equilibrium conditions were used to evaluate the adequacy of the Fick, Weibull and Peleg's equation. As the data was shown in Table 1-4, which present three equations' parameter obtained from nonlinear regression analysis. The coefficient of determination

Table 4. Mass transfer characteristics of white radish during osmotic treatment by Peleg's equation

\begin{tabular}{|c|c|c|c|c|c|c|c|c|c|}
\hline \multirow{2}{*}{ Salt (\%) } & \multirow{2}{*}{ Sucrose (\%) } & \multicolumn{4}{|c|}{ Water loss } & \multicolumn{4}{|c|}{ Solid gain } \\
\hline & & $k_{1}$ & $k_{2}$ & $\mathbf{R}^{2}$ & P (\%) & $k_{1}$ & $k_{2}$ & $\mathbf{R}^{2}$ & $\mathbf{P}(\%)$ \\
\hline & 10 & 1.642 & 0.943 & 98.41 & 2.777 & 1.652 & 0.883 & 97.64 & 3.174 \\
\hline \multirow{2}{*}{2} & 15 & 1.709 & 0.952 & 98.89 & 2.202 & 1.142 & 0.945 & 99.01 & 1.913 \\
\hline & 10 & 2.141 & 0.858 & 99.44 & 1.417 & 1.028 & 0.980 & 99.21 & 1.725 \\
\hline \multirow{2}{*}{3} & 15 & 1.792 & 0.911 & 99.41 & 1.627 & 0.521 & 0.979 & 98.88 & 2.183 \\
\hline & 10 & 2.392 & 0.881 & 99.36 & 1.627 & 0.978 & 0.987 & 98.61 & 2.236 \\
\hline \multirow[t]{2}{*}{4} & 12.5 & 2.159 & 0.943 & 99.59 & 1.179 & 1.042 & 0.949 & 99.04 & 1.829 \\
\hline & 15 & 1.760 & 0.936 & 99.31 & 1.687 & 0.643 & 0.944 & 98.22 & 2.484 \\
\hline
\end{tabular}

Note: $\mathrm{k}_{1}$ and $\mathrm{k}_{2}$ are Peleg constants 
of the Fick, Weibull and Peleg's equation ranging 96.1398.99\%, 90.19-97.84\%; 98.12-99.56\%, 97.79-99.15\%; 98.4199.59\%, 97.64-99, 21\% for SG and WL respectively, indicated that a good fit to the experimental data. The average relative error $(\mathrm{P}, \%)$ values for each experimental condition investigated are also given. The criteria for selected model are the high values of $R^{2}$ and the small values of $P$. Besides, the complex of model is also considered, the models with very complex mechanisms find it difficult to represent the experimental validation owing to the number of parameters involved in the models. Based on the standard criteria suggest that Peleg's equation adequately describes mass transfer kinetics terms during osmotic dehydration of white radishes at given solution concentrations. In fact, in Figure $2 a \& 2 b$, lines representing the fit of the Peleg's equation to the experimental data are plotted with the high correlation.

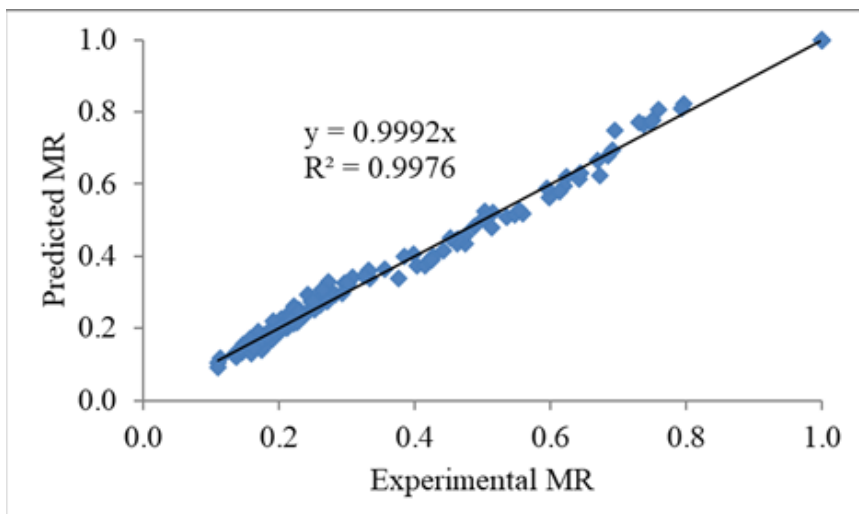

a. Water loss ratio

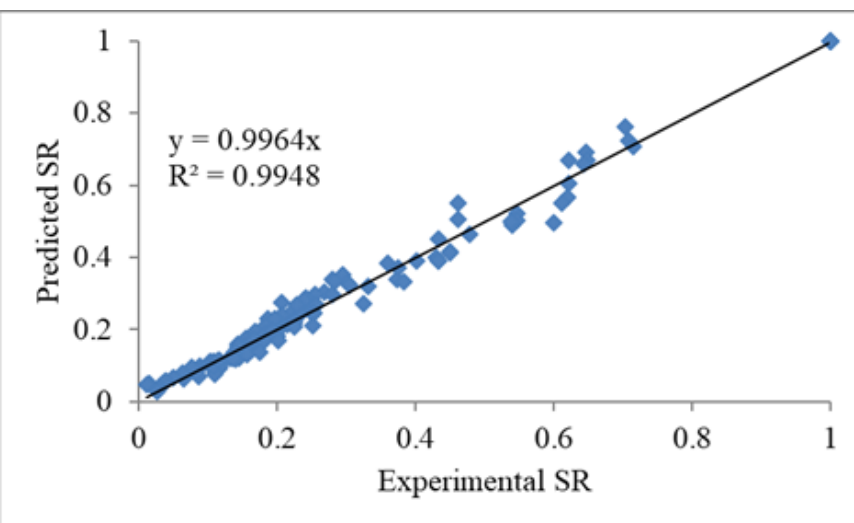

b. Solid gain ratio

Fig. 2. Comparison between the experimental and Peleg's model predicted of water loss (a) and solid gain (b) rate of white radish during osmotic treatment.

\section{Conclusion}

The influence of water loss and solid absorption rate in the osmotic dehydration of white radish was directly related to the osmotic solution concentration, express from mass transfer characteristics. Peleg's equation gave the best fitting for water loss and solid uptake experimental data and adequately used in describing the kinetics of mass transfer at the studied range. Therefore, this equation could be applied to simulate the kinetics of mass transfer during osmotic dehydration process in the range of salt/sugar solution that was investigated.

\section{Authors contributions}

NTNT and NVT carried out the experiment studies. NMT, VQM, PTV drafted the manuscript and conceived of the study and participated in its design and coordination. NVT drafted the manuscript and participated in the design of the study and performed the statistical analysis. All authors read and approved the final manuscript.

\section{Compliance with ethical standards}

Conflict of interest: Authors do not have any conflict of interests to declare.

Ethical issues: None.

\section{References}

1. Gutiérrez RMP, Perez RL. Raphanus sativus (Radish): their chemistry and biology. The Scientific World Journal. 2004;4:811.https://doi.org/10.1100/tsw.2004.131

2. Gilani $A H$, Ghayur MN. Pharmacological basis for the gut stimulatory activity of Raphanus sativus leaves. Journal of Ethnopharmacology. 2004;95(2-3):169-72. https:// doi.org/10.1016/j.jep.2004.06.038

3. Baek SH, Park M, Suh JH, Choi HS. Protective effects of an extract of young radish (Raphanus sativus L.) cultivated with sulfur (sulfur-radish extract) and of sulforaphane on carbon tetrachloride-induced hepatotoxicity. Bioscience, Biotechnology and Biochemistry. 2008;72(5):1176-82. https://doi.org/10.1271/ bbb. 70545

4. Castro-Torres IG, De la O-Arciniega M, Gallegos-Estudillo J, Naranjo-Rodríguez EB, Domínguez-Ortíz MÁ. Raphanus sativus L. var. niger as a source of phytochemicals for the prevention of cholesterol gallstones. Phytotherapy Research. 2014;28(2):16771. https://doi.org/10.1002/ptr.4964

5. Aires A, Mota VR, Saavedra MJ, Rosa EAS, Bennett RN. The antimicrobial effects of glucosinolates and their respective enzymatic hydrolysis products on bacteria isolated from the human intestinal tract. Journal of Applied Microbiology. 2009;106(6):2086-95. https://doi.org/10.1111/ j.1365-2672.2009.04180.x

6. Scholl C, Eshelman BD, Barnes DM, Hanlon PR. Raphasatin is a more potent inducer of the detoxification enzymes than its degradation products. Journal of Food Science. 2011;76(3):C504C511. https://doi.org/10.1111/j.1750-3841.2011.02078.x

7. Nishadh A, Mathai L. Osmotic dehydration of radish in salt and sucrose solutions. International Journal of Innovative Research in Science, Engineering and Technology. 2014;3(1):1514-21.

8. Lazarides HN, Katsanidis E, Nickolaidis A. Mass transfer during osmotic preconcentration aiming at minimal solid uptake. Journal of Food Engineering. 1995;25:151-66. https:// doi.org/10.1016/0260-8774(94)00006-U

9. Sutar PP, Prasad S. Optimization of osmotic dehydration of carrots under atmospheric and pulsed microwave vacuum conditions. Drying Technology. 2011;29(3):371-80. https:// doi.org/10.1080/07373937.2010.497955

10. Bera D, Roy L. Osmotic dehydration of litchi using sucrose solution: effect of mass transfer. Journal of Food Processing and Technology. 2015;6(7):462-69.

11. Tortoe C. A review of osmodehydration for food industry.African Journal of Food Science. 2010;4(6):303 - 24. Available from: http://www.academicjournals.org/ajfs

12. Sahoo PK, Sharma AK. Modelling of water loss and solute uptake 
during osmotic drying of carrots using weibull distribution approach. International Food Research Journal. 2018;25(1): 27074.

13. Peleg M. An empirical model for the description of moisture sorption curves. Journal of Food Science. 1998;53(4):1216-17. https://doi.org/10.1111/j.1365-2621.1988.tb13565.x

14. Doymaz I, İsmail O. Drying characteristics of sweet cherry. Food and Bioproducts Processing. 2011;89(1):31-38. https:// doi.org/10.1016/j.fbp.2010.03.006

15. Azuara E, Beristain Cl, Gutiérrez GF. A method for continuous kinetic evaluation of osmotic dehydration. LWT-Food Science and Technology. 1998;31(4):317-21. https://doi.org/10.1006/ fstl.1997.0364

16. Chenlo F, Moreira R, Fernández-Herrero C, Vázquez G. Mass transfer during osmotic dehydration of chestnut using sodium chloride solutions. Journal of Food Engineering. 2006;73(2): 16473. https://doi.org/10.1016/j.jfoodeng.2005.01.017

17. İspir A, Toğrul iт. Osmotic dehydration of apricot: Kinetics and the effect of process parameters. Chemical Engineering Research and Design. 2009;87(2):166-80. https://doi.org/10.1016/ j.cherd.2008.07.011

18. Nuñez-Mancilla Y, Perez-Won M, Vega-Gálvez A, Arias V, TabiloMunizaga G, Briones-Labarca V, Di Scala K. Modeling mass transfer during osmotic dehydration of strawberries under high hydrostatic pressure conditions. Innovative Food Science and Emerging Technologies. 2011;12(3):338-43. https:// doi.org/10.1016/j.ifset.2011.03.005

19. Park KJ, Bin A, Brod FPR, Park THKB. Osmotic dehydration kinetics of pear D'anjou (Pyrus communis L.). Journal of Food Engineering. 2002;52(3):293-98. https://doi.org/10.1016/S02608774(01)00118-2

20. Corzo O, Ramírez O y Brach N. Aplicación del modelo de Peleg en el estudio de la transferencia de masa durante la deshidratación osmótica de láminas de mamey (Mammea americana) saber. Revista Multidisciplinaria delConsejo de Investigación de la Universidad de Oriente, [enlínea]. 2008;20(1):87-95. Available from: http://www.redalyc.org/articulo.oa?id=427739437013

21. Azoubel PM, Murr FEX. Mass transfer kinetics of osmotic dehydration of cherry tomato. Journal of Food Engineering. 2004;61(3):291-95. https://doi.org/10.1016/S02608774(03)00132-8

22. El-Aquar ÂA, Murr FEX. Estudo e modelagem da cinética de desidrataçãoosmótica do mamãoformosa (Carica papaya L.). Food Science and Technology. 2003;23:69-75. https:// doi.org/10.1590/S0101-20612003000100015

23. Corzo O, Gomez ER. Optimization of osmotic dehydration of cantaloupe using desired function methodology. Journal of Food Engineering. 2004;64(2):213-19. https://doi.org/10.1016/ j.jfoodeng.2003.09.035

24. daConceição Silva MA, da Silva ZE, Mariani VC, Darche S. Mass transfer during the osmotic dehydration of West Indian cherry. LWT-Food Science and Technology. 2012;45(2):246-52. https://doi.org/10.1016/j.lwt.2011.07.032

25. GelyMC, Santalla EM. Moisture diffusivity in quinoa (Chenopodium quinoa Willd.) seeds: Effect of air temperature and initial moisture content of seeds. Journal of Food Engineering. 2007;78(3):1029-33. https://doi.org/10.1016/ j.jfoodeng.2005.12.015

26. Cunha LM, Oliveira FA, Aboim AP, Frías JM, Pinheiro-Torres A.
Stochastic approach to the modelling of water losses during osmotic dehydration and improved parameter estimation. International Journal of Food Science and Technology. 2001;36(3):253-62. https://doi.org/10.1046/j.13652621.2001.t01-1-00447.x

27. García-Pascual P, Sanjuán N, Melis R, Mulet A. Morchella esculenta (morel) rehydration process modelling. Journal of Food Engineering. 2006;72(4):346-53. https://doi.org/10.1016/ j.jfoodeng.2004.12.014

28. Sannaveerappa T, Ammu K, Joseph J. Protein-related changes during salting of milkfish (Chanoschanos). Journal of the Science of Food and Agriculture. 2004;84(8):863-69. https:// doi.org/10.1002/jsfa.1682

29. Gallart-Jornet L, Barat JM, Rustad T, Erikson U, Escriche I, Fito P. A comparative study of brine salting of Atlantic cod (Gadus morhua) and Atlantic salmon (Salmo salar). Journal of Food Engineering. $\quad$ 2007;79(1):261-70.https://doi.org/10.1016/ j.jfoodeng.2006.01.053

30. Mayor L, Moreira R, Chenlo F, Sereno AM. Kinetics of osmotic dehydration of pumpkin with sodium chloride solutions. Journal of Food Engineering. 2006;74,253-62. https://doi.org/10.1016/ j.jfoodeng.2005.03.003

31. Moreira R, Chenlo F, Torres MD, Vazquez G. Effect of stirring in the osmotic dehydration of chestnut using glycerol solutions. LWT Food Science and Technology. 2007;40,1507-14. https:// doi.org/10.1016/j.lwt.2006.11.006

32. Bchir B, Besbes S, Karoui R, Paquot M, Attia H, Blecker C. Osmotic dehydration kinetics of pomegranate seeds using date juice as an immersion solution base. Food and Bioprocess Technology. 2012;5(3):999-1009.https://doi.org/10.1007/s11947010-0442-1

33. Sachetti G, Gianotti A, Dalla Rosa M. Sucrose-salt combined effects on mass transfer kinetics and product acceptability. Study on apple osmotic treatments. Journal of Food Engineering. 2001;49(2-3):163-73. https://doi.org/10.1016/S02608774(00)00206-5

34. Ganjloo A, Rahman RA, Osman A, Bakar J, Bimakr M. Kinetics of crude peroxidase inactivation and color changes of thermally treated seedless guava (Psidium guajava L.). Food and Bioprocess Technology. 2011;4(8):1442-49. https:// doi.org/10.1007/s11947-009-0245-4

35. Phisut N. Factors affecting mass transfer during osmotic dehydration of fruits. International Food Research Journal. 2012;19 (1):177-82 